\title{
AVALIAÇÃO DO ESTUDANTE DE MEDICINA
}

\author{
ASSESSMENT OF MEDICAL STUDENTS
}

Luiz Ernesto de Almeida Troncon

Docente do Departamento de Clínica Médica e Vice-Presidente da Comissão de Graduação da Faculdade de Medicina de Ribeirão Preto da Universidade de São Paulo.

Correspondência: Prof.Dr. Luiz Ernesto de Almeida Troncon. Hospital das Clínicas da Faculdade de Medicina de Ribeirão Preto da Universidade de São Paulo, Departamento de Clínica Médica - CEP: 14048-900 Ribeirão Preto - SP - Telefone: 016 - 633 - 0436 FAX: 016-633-1144.

TRONCON LE de A. Avaliação do estudante de medicina. Medicina, Ribeirão Preto, 29:429-439, out./dez. 1996.

RESUMO: A avaliação do estudante de Medicina cumpre um papel central na sua educação e constitui uma das funções mais importantes da escola médica. A avaliação pode ser definida como um processo de obtenção de informações, visando à tomada de medidas para o aprimoramento do processo educacional e à interferência positiva no aprendizado do estudante. Deve incidir sobre aspectos relevantes e ser conduzida com métodos objetivos, em condições padronizadas, em circunstâncias viáveis e de aceitação indiscutível por todos os envolvidos na avaliação. A avaliação abrangente do estudante de Medicina deveria cobrir os aspectos cognitivos, as habilidades e as competências práticas necessárias ao exercício da profissão, bem como as atitudes e as características pessoais dos alunos. Modernos métodos, como o exame clínico objetivo, estruturado por estações, o exame de desempenho clínico e o emprego de pacientes padronizados permitem as avaliações válidas, fidedignas e viáveis das principais competências clínicas dos estudantes de Medicina. Na maior parte das escolas médicas, a ênfase na avaliação dos aspectos cognitivos e a prioridade dada às avaliações somativas, com caráter de prêmio ou punição aos examinandos, tem contribuído para uma imagem negativa das práticas de avaliação e tem provocado distorções na educação dos estudantes. $O$ uso mais extensivo de modalidades formativas e a escolha judiciosa de métodos mais adequados, válidos e fidedignos, podem contribuir para restaurar as funções educacionais mais genuínas da avaliação do estudante de Medicina.

UNITERMOS: Avaliação. Competência Clínica. Estudantes de Medicina. Educação Médica.

\section{INTRODUÇÃO}

A avaliação do estudante constitui, possivelmente, a etapa de maior relevância em todo o processo educacional. Permite a obtenção de informações sobre o aprendizado e subsidia a tomada de decisões que, muitas vezes, são críticas para a vida do estudante. Além disso, a forma e o conteúdo das avaliações são altamente importantes, na medida em que constituem um poderoso determinante de como os alunos estudam e aprendem ${ }^{1,2,3}$.
No caso específico do estudante de Medicina, a avaliação reveste-se de importância especial, visto que deve contemplar não só o conhecimento adquirido, mas também habilidades específicas e elementos de ordem afetiva, como as atitudes frente a inúmeros aspectos da prática profissional. O reconhecimento progressivo desta importância tem propiciado um grande desenvolvimento da área de Avaliação de Competências Médicas, dentro do campo geral da Educação Médica. Esta evolução tem resultado em uma diversidade de conceitos e de métodos aplicáveis a situa- 
ções específicas na avaliação do estudante, bem como no aumento da complexidade e da dificuldade inerente à área.

Neste artigo, pretende-se rever alguns conceitos básicos relativos à avaliação no contexto educacional, apresentar os fundamentos de novos métodos de avaliação objetiva de competências médicas, bem como tecer considerações sobre o uso corrente e as funções ideais da avaliação do estudante de Medicina.

\section{CONCEITOS BÁSICOS}

\subsection{Aspectos Gerais}

A avaliação é um processo que encontra lugar em toda e qualquer atividade humana. Pode ser, gene ricamente, definida como a determinação do valor de alguma coisa para uma certa finalidade ${ }^{4}$. No contexto educacional, a avaliação implica em obter informações, por meio da aplicação de métodos específicos, que podem subsidiar a tomada de decisões que interessam tanto ao processo do aprendizado como ao educando. Ainda neste contexto, a avaliação pode ser entendida como "um processo de comparação entre os dados do desempenho do estudante e os objetivos instrucionais previamente estabelecidos" ${ }^{5}$. Estas definições, ligeiramente diferentes, trazem consigo alguns componentes básicos indissociáveis do conceito genérico de avaliação. Entre estes, deve ser ressaltado o juízo de valor, aplicado sobre os resultados do emprego de métodos apropriados, tendo em vista padrões pré-estabelecidos. Muito freqüentemente, o juízo é estabelecido com base na apreciação de medidas feitas com escalas apropriadas, em comparação a critérios quantitativos previamente definidos $^{6}$. Em qualquer caso, a valoração é feita com vistas a finalidades específicas, que justificam e norteiam a avaliação.

Com relação à avaliação do estudante de Medicina, pode ser adotado o conceito genérico de que esta é um processo de colheita de informações, realizado por meio de atividades sistemáticas e formais, que permite saber o que o estudante conhece, sabe fazer e, efetivamente, faz de modo adequado, de maneira que se possa interferir no processo educacional, corrigindo distorções e reforçando aspectos positivos. Evidentemente, esta interferência deve repercutir sobre o sujeito principal do processo educacional, o estudante de Medicina.

Uma importante decorrência destes conceitos é que a avaliação pressupõe o estabelecimento pré- vio, com a maior precisão possível, do conjunto de habilidades que devem ser adquiridas, cujo domínio, demonstrado na avaliação pertinente, permitirá atestar a consecução dos objetivos instrucionais.

\subsection{Finalidades e momento da avaliação}

No desenvolvimento do processo educacional, a avaliação do estudante pode ser efetuada em diferentes momentos, com finalidades distintas ${ }^{7}$. De acordo com estas variáveis, é possível classificar os processos de avaliação em 3 diferentes tipos.

A avaliação localizatória é a tomada de informações, efetuada no início do processo educacional, com vistas à verificação do grau de domínio preliminar dos objetivos instrucionais, ou, ainda, daqueles que constituem pré-requisitos para a aquisição dos conhecimentos e habilidades, cujo ensino se seguirá. Por conseguinte, este tipo de avaliação tem forte repercussão no planejamento das atividades educacionais.

A avaliação formativa é aquela realizada, regular e periodicamente, ao longo do processo educacional, para obter dados sobre o progresso conseguido e, deste modo, efetivar a oportuna correção das distorções observadas, preencher as lacunas detectadas, bem como reforçar as conquistas realizadas. Uma importante característica deste tipo de avaliação é o "feedback" imediato que deve ser fornecido ao estudante, de modo a poder configurar o processo de obtenção de dados como genuína atividade educacional. Em determinadas circunstâncias, a aplicação repetida de métodos de avaliação formativa pode fornecer resultados indicativos da ocorrência de problemas ou dificuldades específicas de aprendizado. Nestes casos, podem ser empregados recursos de avaliação diagnóstica para a detecção, confirmação e caracterização destes problemas, de modo a se dispor de dados para a sua solução.

A avaliação somativa, também denominada de terminal, incide no final ou após o transcurso do processo educacional, ou de suas etapas mais importantes, tendo, como finalidade, a verificação do grau atingido de domínio dos objetivos instrucionais. E, freqüentemente, empregada com o propósito de aprovação ou reprovação do estudante ou, ainda, de emitir parecer formal sobre a capacitação individual para o exercício de atividades profissionais.

\subsection{Características dos instrumentos de avaliação}

O instrumento ideal de avaliação deve possuir três atributos fundamentais: deve ser válido, fidedigno e viável ${ }^{6,7}$. 
A validade de um instrumento ou método de avaliação é a sua capacidade de avaliar, efetivamente, o "que" deve realmente ser avaliado. O conceito de validade abrange várias modalidades (conteúdo, estatística, preditiva e de construto), cuja discussão extrapola os limites deste artigo. Vale ressaltar, entre tanto, pela sua importância, a validade de conteúdo. Esta se relaciona com a relevância do que é avaliado. Como, em muitas situações, não é possível fazer com que a avaliação incida sobre todos os tópicos de maior relevância, a validade da avaliação vai depender, em grande parte, da representatividade das amostras dos itens escolhidos.

A fidedignidade do método de avaliação é uma característica que se relaciona à precisão, à acurácia, à objetividade, à reprodutibilidade do instrumento, fatores estes que, por sua vez, determinam a confiabilidade e a consistência dos resultados obtidos. Refere-se, portanto, ao "como" avaliar. Uma avaliação fidedigna implica no máximo controle possível de um número de variáveis de três ordens diferentes. Estas são ligadas, respectivamente, ao avaliador (subjetividade, fatores afetivos, grau de capacitação para a função de avaliar, etc...), ao avaliando (estado emocional, experiência prévia com o método a ser empregado, etc...) e, em especial, aos componentes do próprio método, como ambiente, material e situação a serem utilizados na aplicação do instrumento.

A viabilidade ou praticidade do método de avaliação é uma característica que se relaciona a sua possibilidade de execução e a sua aceitação por parte de todos os envolvidos no processo de avaliação. De pende de requisitos variados, como condições de es paço, tempo, material de apoio, etc..., que implicam em adequado planejamento, conveniente organização e apropriado controle de custos.

\section{COMPETÊNCIAS, HABILIDADES E ATRI- BUTOS DO ESTUDANTE DE MEDICINA}

O estudante de Medicina, assim como os de outros cursos voltados às profissões da Saúde Humana, deve não só adquirir um conjunto de conhecimentos fundamentais, como também deve dominar uma diversidade de habilidades de complexidade variável, que nem sempre são de fácil avaliação. Na área da Educação Médica, e, em especial, na de avaliação dos estudantes de Medicina, o foco de atenção tem se dirigido para o que se denomina de competências médicas. A competência é, em geral, definida como um conjunto de habilidades de natureza intelectual ou física, relevante para um determinado fim, passível de ser ensinada, aprendida e avaliada Numa das taxonomias de objetivos educacionais de maior aceitação ${ }^{9}$, as habilidades podem ser descritas como pertencentes a três grandes domínios: o cognitivo, o psicomotor e o afetivo.

O domínio cognitivo refere-se às habilidades de natureza puramente intelectual, como a aquisição de conhecimento, a compreensão, a análise e a capacidade de síntese, entre outras. As habilidades psicomotoras são as que demandam os órgãos do sentido e a efetuação neuromuscular para o desempenho de tarefas específicas. Por sua vez, o domínio afetivo compreende as atitudes, as crenças, os valores e os juízos acerca das coisas, que, por sua vez,funcionam como importantes determinantes da emissão de comportamentos específicos, que são, em geral, favoráveis, desfavoráveis ou neutros em relação à prática profissional.

Na Educação Médica, as competências envolvidas constituem, quase sempre, habilidades complexas e que compreendem interrelações variadas entre os domínios cognitivos, psicomotor e afetivo. Por exemplo, a comunicação efetiva com os pacientes e seus familiares, a obtenção da anamnese e a execução do exame físico envolvem habilidades de todas as mencionadas categorias. Do mesmo modo, a interpretação adequada das informações obtidas e a sua análise visando à solução de problemas, bem como a cor respondente tomada de decisões, envolvem não só habilidades cognitivas complexas, como também atitudes e crenças frente aos padrões de conduta médica.

Além disso, o exercício das habilidades definidoras de uma competência é influenciado por fatores diversos, como, por exemplo, o contexto (crianças, adultos, idosos), o conteúdo envolvido (condições de natureza variada, relacionadas a diferentes órgãos e aparelhos), as circunstâncias de cada situação (gravidez, acidentes), bem como as características de personalidade do médico (Ou estudante) e o efeito modulador de experiências prévias semelhantes.

Um exemplo de um conjunto de competências médicas, baseadas nos Objetivos Educacionais da Faculdade de Medicina de Ribeirão Preto ${ }^{10}$ é apresentado na Tabela I.

Ao lado da aquisição de proficiência nas diferentes competências médicas, anteriormente abordadas, é desejável que o estudante de Medicina detenha alguns atributos pessoais de caráter positivo, como a hones- 
tidade, a integridade, a capacidade de sentir compaixão pelo próximo, o espírito da iniciativa, a tolerância, etc... ${ }^{11}$. Do mesmo modo, em uma pro fissão cujo objeto central de atuação é a saúde das pessoas, é altamente desejável que o futuro profissional seja desprovido de características pessoais negativas, como a desonestidade, o egoísmo, o espírito preconceituoso, etc. Assim sendo, a avaliação abrangente do estudante de Medicina deveria cobrir todas estas habilidades, competências e características pessoais em seus diferentes domínios. Isto, obviamente, somente seria possível mediante o emprego de uma diversidade de métodos e de instrumentos voltados para aspectos específicos.

Tabela I - Exemplos de competências necessárias ao exercício da Medicina

1. Compreensão da variabilidade interindividual dos fenômenos biológicos e psicológicos.

2. Compreensão do papel do ambiente e dos fatores sociais na manutenção da saúde e na produção das doenças.

3. Compreensão da inserção do indivíduo na família, na comunidade e na sociedade.

4. Compreensão do papel do médico na promoção da saúde, na prevenção das doenças, na reabilitação das pessoas deficientes e no avanço do conhecimento científico.

5. Comunicação adequada com o paciente e seus familiares.

6. Obtenção da história clínica e realização do exame físico com técnicas adequadas.

7. Aplicação do raciocínio clínico na identificação e na solução de problemas de saúde.

8. Aplicação das medidas necessárias para manter a vida em casos de urgência.

9. Comunicação verbal e escrita com seus colegas médicos e com outros profissionais da saúde.

10. Reconhecimento das limitações da sua competência e tomada das medidas necessárias para o adequado encaminhamento dos pacientes a seus cuidados.

\section{MÉTODOS DE AVALIAÇÕES}

Como anteriormente mencionado, existem métodos disponíveis para a avaliação de uma variedade de habilidades, incluindo as afetivas, bem como para a determinação da ocorrência de qualidades pessoais positivas e negativas. Nesta secção, por razões de espaço, serão tecidas considerações apenas sobre al- gumas técnicas disponíveis para a avaliação de aspectos cognitivos e serão descritas as bases de métodos, mais modernos, de avaliação das competências e habilidades clínicas dos estudantes de Medicina.

\subsection{Aspectos Cognitivos}

A avaliação do conhecimento adquirido pelo estudante constitui, possivelmente, a modalidade mais freqüentemente empregada e sobre a qual se dispõe, provavelmente, de maior experiência acumulada. A Tabela II apresenta uma relação dos principais recursos disponíveis para a avaliação das habilidades cognitivas. A descrição pormenorizada de cada um, ou a discussão dos seus princípios e as recomendações inerentes a sua aplicação extrapolam os limites deste trabalho e encontram-se disponíveis em fontes bibliográficas de maior profundidades ${ }^{6,7}$.

Cumpre, porém, ressaltar que, na avaliação do estudante de Medicina, a abordagem dos aspectos cognitivos deve contemplar não só a retenção do conhecimento factual adquirido, mas as habilidades mais complexas, relacionadas ao raciocínio clínico e à com preensão dos temas médicos, em profundidade, e, em especial, à aplicação do conhecimento adquirido, na solução de problemas concretos. Neste sentido, é de interesse mencionar as provas orais e os "problemas de manejo de pacientes" que se acoplam aos exames de desempenho clínico, conforme o que será adiante descrito, e que cumprem, aparentemente, este papel integrador.

Deve ser, também, salientado o interesse em se avaliar não só o que o estudante aprendeu, mas se ele "aprendeu a aprender". Este aspecto é da maior atualidade, face à rapidez com que os conceitos mudam na Medicina e à enorme velocidade com que o conheci mento médico se acumula. Assim sendo, o estudante deve ter uma atitude de aprendizado contínuo, como também deve dominar as habilidades necessárias à busca de informações nas fontes adequadas, usando os re cursos convenientes. Para avaliar apropriadamente esta competência, desenvolveu-se, na Universidade McMaster, no Canadá, o teste do "salto triplo"1,12. Na primeira fase desta modalidade de avaliação, é apresentado ao estudante um problema escrito, sobre o qual se baseia uma prova oral. Nesta, o estudante não só deve demonstrar o que "sabe", mas deve identificar o que "não sabe", e fazer um planejamento de tarefas voltadas ao aprendizado futuro imediato. A segunda fase é cumprida exclusivamente pelo estudante, na busca do referido aprendizado junto às fon- 
tes apropriadas. Na terceira e última etapa, novamente em formato de prova oral, o estudante relata o que aprendeu, reportando, também, em que fontes se baseou para adquirir o conhecimento. $O$ teste é encerrado com uma apreciação crítica, de caráter formativo, do examinador sobre o desempenho do estudante, tendo como foco o conhecimento adquirido e os meios utilizados para a consecução das metas anteriormente traçadas. Deste modo, esta forma de avaliação, que visa, prioritariamente, medir o conhecimento adquirido e a proficiência na sua aquisição, contribui, de imediato, para o reforço do estudante e para o desenvolvimento de uma atitude favorável ao auto-aprendizado.

Tabela II - Principais recursos para avaliação de habilidades cognitivas

\section{Provas escritas}

- questões com respostas restritas

- questões com respostas extensas

- ensaio discursivo

- exercícios interpretativos

\section{Provas objetivas}

2.1. Com seleção de respostas fornecidas

- tipo falso/verdadeiro

- tipo associação

- testes de múltipla escolha

2.2. Com fornecimento de respostas pelo aluno

- respostas curtas

- completar frases

- preencher lacunas

3. Formas alternativas

- estudo de casos

- relatórios

- elaboração de projetos

- revisões e críticas

- provas orais

- problemas de manejo de pacientes

\subsection{Competências e habilidades clínicas}

A avaliação das habilidades e das competências clínicas desempenha um papel central na educação do estudante de Medicina e constitui, possivelmente, o campo de expansão mais rápida, na área do conheci mento de Avaliação em Educação Médica.

A avaliação das habilidades e das competências clínicas deve recair sobre os aspectos da prática profissional mais voltados aos cuidados do paciente, desde a obtenção da história clínica até a orientação dos familiares e a educação do paciente com relação à sua própria saúde. Dependendo das suas finalidades, do momento da sua aplicação e do contexto em que se desenvolve, a avaliação pode ser feita, empregando-se uma variedade de métodos, conforme se apresenta na Tabela III.

As observações assistemáticas consistem no registro ocasional dos pontos positivos e negativos do desempenho do estudante, ao longo de um determinado período de tempo ${ }^{7}$. Já as observações sistemáticas empregam um instrumento, previamente definido, que contém, explicitamente, a relação das habilidades e das competências a serem avaliadas e as respectivas alternativas de preenchimento. Estas, habitualmente, constituem juízos de valor sobre o desempenho do estudante, assinalados em escala que varia do "muito ruim" ao "excelente" ou, alternativamente, registrados em escala binária do tipo "satisfatório" ou "insatisfatório", para cada uma das inúmeras habilidades a serem avaliadas. Podem incluir itens relativos a atitudes (por exemplo, a preocupação com o bem-estar do paciente) e a outros atributos do estudante (por exemplo, o interesse ou o empenho no próprio aprendizado $)^{7,13}$. Tipicamente, estes métodos são aplicados no decorrer do desenvolvimento dos estágios clínicos, empregando, como avaliadores, os profissionais encarregados da supervisão das atividades dos estudantes. Podem prestar-se a qualquer das finalidades gerais de avaliação, anteriormente mencionadas, mas sua função ideal é, possivelmente, a formativa, visto que servem, com muita propriedade, ao registro dos pontos que devem ser reforçados ou daqueles que constituem deficiências a serem sanadas. Por outro lado, não têm configuração ideal à função somativa, visto que há componente de subjetividade muito importante, dependente do contacto contínuo e regular do avaliando com o avaliado; bem como da necessária interação destas partes no próprio desenvolvimento do processo educacional ou do treinamento clínico. Além disso, as condições, em que a observação dos diferentes estudantes se dá, não comportam padronização apropriada para a função somativa.

Os exames de desempenho consistem na observação dos comportamentos do estudante, indicativos do domínio de determinadas habilidades, quando da execução de tarefas predeterminadas ${ }^{14}$. Os principais componentes destes métodos são, além do examinador e do examinando, o paciente, o instrumento onde os comportamentos são registrados e as tarefas atribuídas ao examinando. Na modalidade denomina- 
da "caso longo", o examinando recebe um conjunto de tarefas que, em geral, compreende todas aquelas que o médico deve cumprir, desde a obtenção da história clínica, a realização do exame físico e a conclusão da consulta, com a informação do paciente sobre o que pensa da situação e o que será necessário fazer em seguida. Já na modalidade "caso curto", as diferentes tarefas devem ser cumpridas em diferentes pacientes. Estes dois tipos de exame são, freqüentemente, complementados por provas orais em que os estudantes podem explicitar suas impressões diagnósticas ou declinar as medidas necessárias à solução dos problemas, bem como demonstrar o domínio dos diferentes aspectos cognitivos relacionados ao caso em questão.

Ainda que estas modalidades mais tradicionais de avaliação possam fornecer dados relevantes sobre o nível de competência clínica dos estudantes, carecem-nas de maior objetividade e de padronização. Os resultados obtidos são, é evidente, muito fortemente influenciados pelo tipo de paciente disponível para um determinado exame e toda a avaliação depende muito do avaliador. Além disso, cada estudante é avaliado em condições muito diferentes, o que dificulta a comparação dos resultados de uns com os dos outros. Estas particularidades concorrem para que estes métodos sejam considerados como de reduzida fidedignidade. Vários estudos mostram que a qualidade do desempenho do examinando varia muito em diferentes situações, sendo muito dependente dos conteúdos envolvidos em cada caso Por outro lado, o maior mérito desta modalidade de avaliação é a sua validade, uma vez que as situações selecionadas e as tarefas que o aluno deve desempenhar são, de modo geral, bem representativas da prática profissional.

Procurando aumentar a fidedignidade desta modalidade tradicional de avaliação de competências clínicas, mantendo sua alta validade, algumas modificações foram recentemente propostas por Gleeson ${ }^{16}$. na descrição do que se denominou de O.S.L.E.R. "Objective Structural Long Examination Record". Nesta proposição, recomenda-se, para cada avaliação:

a- o emprego de, pelo menos, dois casos longos em sequiência;

b- a atuação simultânea de, pelo menos, dois observadores diferentes;

c- e, especialmente, o uso de um instrumento padronizado, no qual o número e o tipo de julgamentos a serem feitos pelos dois examinadores, em cada caso clínico, é predefinido e compreende conjunto suficientemente amplo de itens relevantes de observação ${ }^{17}$.

No entanto, as deficiências inerentes ao uso destas modalidades mais tradicionais e habituais de avaliação de habilidades clínicas, tem levado ao desenvolvimento de técnicas que procuram garantir maior objetividade e padronização das condições de exame, resultando, por conseguinte, em níveis mais elevados de fidedignidade. Vale destacar dois destes métodos, que têm sido crescentemente utilizados e estudados em países mais desenvolvidos. O primeiro deles é aO.S.C.E. - "Objective Structured Clinical Examination" 18,19 que, recentemente, foi introduzido em nosso meio com a denominação de "exame clínico estruturado por estações ${ }^{20}$. O segundo destes métodos é a C.P.E. - "Clinical Performance Examination"21. Ambos os métodos lançam mão de uma outra técnica específica que é a dos S.P. -"Standardized Patients"22, expressão que, em nosso meio, recebeu a denominação de "Pacientes padronizados" ${ }^{20}$. A alta importância destas modalidades de avaliação de habilidades e de competências clínicas justifica a sua abordagem em separado.

\section{Tabela III - Principais recursos para avaliação de} competências e habilidades clínicas

1. Observações assistemáticas

- relato anedótico

2. Observações sistemáticas

- escalas de classificação global

3. Exames de desempenho

- casos curtos

- casos longos

- exame objetivo estruturado por estações

- exame de desempenho clínico

\subsubsection{O exame clínico objetivo estruturado por estações}

Este método de avaliação de habilidades clínicas foi desenvolvido há mais de 20 anos, na Escócia”, e tem ganhado crescente aceitação e difusão por todo o mundo Nesta técnica de exame, os examinandos percorrem diferentes estações em que são solicitados a desempenhar tarefas clínicas distintas, como, por exemplo, obter uma história clínica focalizada, realizar parte ou todo o exame de um órgão ou aparelho, inspeccionar uma radiografia, analisar um traçado 
eletrocardiográfico, ou instruir um paciente sobre o seu diagnóstico. Em cada estação, permanecem um tempo predeterminado, realizando a tarefa solicitada, sob a observação de um avaliador que emprega um instrumento de registro pré-elaborado. Este consta de um protocolo de observação, contendo os comporta mentos esperados do aluno, cuja ocorrência irá demonstrar o domínio das habilidades em exame. Ao término do tempo previsto, quando se emite um sinal audível por todos, os estudantes movem-se para a estação seguinte, alternando-se na ocupação das várias estações. Algumas das estações podem incluir subestações de resposta a questões referentes a tarefa recém-realizada. Outras estações podem ser, exclusivamente, de resposta a questões referentes à estação imediatamente precedente.

Esta técnica de avaliação de habilidades clínicas apresenta algumas vantagens altamente desejáveis para a consecução dos seus objetivos. Assim, é possível selecionar o tipo de habilidade a ser avaliada, o nível de complexidade exigido e as circunstâncias da avaliação, sem depender da disponibilidade de casos ou de outros fatores. Isto toma mais fácil preencher o requisito de validade da avaliação. Além disto, a atuação do avaliador, trabalhando com protocolo de observação pré-estabelecido, confere objetividade ao exame. Por fim, todos os examinados são avaliados exatamente nas mesmas condições. Estas características permitem preencher, com mais facilidade, os requisitos de fidedignidade da avaliação.

\subsubsection{O exame de desempenho clínico}

O exame de desempenho clínico foi desenvolvido em escolas americanas, sob a denominação de C.P.E. - "Clinical Practice Examination" corno alternativa de solução de possíveis inconveniências da modalidade O.S.C.E., como a artificialidade e a fragmentação na abordagem dos casos presentes nas suas diferentes estações.

Esta modalidade de avaliação tem configuração geral muito semelhante à da O.S.C.E. Tem, entretanto, como principal diferença em relação àquela, o fato de que, em cada estação, o estudante deve cumprir não uma só tarefa específica, ou um pequeno número delas, mas todo o conjunto de tarefas necessárias para que a abordagem do paciente se complete. Tipicamente, em cada situação, o estudante encontra um paciente que deve ser entrevistado, com vistas à obtenção da sua história clínica e à caracterização do problema de saúde a ser resolvido. Deve ser, tam- bém, submetido ao exame físico e, em seguida, informado e orientado sobre as medidas diagnósticas e terapêuticas necessárias para a solução do referido problema. Se a modalidade O.S.C.E. pode ser comparada a uma sequiência de exames com casos curtos, a modalidade C.P.E. encontra analogia com uma sequiência de casos longos.

A principal vantagem da modalidade C.P.E. é, deste modo, a abordagem integral do caso, em condições mais próximas da realidade da prática profissional. Isto faz com que se preencham os requisitos de validade, sem perder os de fidedignidade, garantidos pela padronização dos casos e pela objetividade da estruturação dos protocolos de observação e da atuação dos examinadores.

Por outro lado, a principal desvantagem daC.P.E. é de ordem operacional. Cada estação típica dura, pelos menos, vinte minutos. Estudos de reprodutibilidade dos resultados e da sua capacidade de generalização indicaram que o número mínimo de estações deva ser de quinze a dezoito' Além disso, o trabalho clínico em cada estação é, habitualmente, seguido de avaliação dos aspectos cognitivos envolvidos no caso, feita na forma de "problema de manejo de paciente", com duração de, pelo menos, outros vinte minutos. Desta maneira, o tempo total de exame é de, no mínimo, dez horas para quinze estações. Isto demanda que a avaliação completa tenha que perdurar por vários dias e implica em que o esforço operacional, para o exame de toda uma turma de estudantes, seja enorme.

\subsubsection{O emprego de pacientes padronizados}

$\mathrm{O}$ emprego de pacientes reais, em atividades de avaliação, apresenta alguns problemas de reconhecida importância. Em primeiro lugar, nem sempre os casos desejados encontram-se disponíveis à época da avaliação. Além disso, o desempenho dos pacientes, durante uma atividade de avaliação, pode ser muito variável. Assim, um mesmo paciente pode relatar as suas queixas a dois estudantes diferentes de modos completamente distintos. Pode, então, dar níveis variados de detalhamento, esquecer ou, ocasionalmente, omitir dados relevantes ou, ainda, imprimir, ao seu relato, tons distintos de emoção. É fato bem conhecido, a partir de estudos empíricos, que muitos pacientes tendem, a deliberadamente, "ajudar" os estudantes, enquanto que outros se antipatizam, de imediato, com o "médico-examinando", e procuram atrapalhá-lo Por fim, os pacientes, como qualquer pessoa sem preparo 
específico para esta finalidade, podem cansar-se de serem inquiridos, repetidamente, sobre sua história clínica ou de serem examinados por vários estudantes. Neste ponto particular, ainda que desejosos de cooperar com atividades educacionais e de avaliação e devidamente informados de sua natureza, os pacientes são pessoas com problemas de saúde que podem afetar a sua disposição e, portanto, compro meter a qualidade do seu desempenho ${ }^{14}$.

Procurando obviar muitos destes inconvenientes, o Professor Howard Barrows iniciou, há mais de três décadas, trabalho de treinamento de alguns pacientes para tomar o seu emprego, em atividades educacionais, mais apropriado $\mathrm{O}$ aprimoramento deste método levou ao conceito atual de paciente padronizado, como uma pessoa normal ou doente (paciente real, estável e em boas condições de saúde) que é adequadamente treinada para protagonizar casos clínicos com características específicas; estes podem, então, ser empregados em atividades de ensino ou, particularmente, na avaliação de habilidades clínicas ${ }^{22}$.

A utilização desta técnica permite superar várias das limitações, acima mencionadas, do emprego de pacientes reais e obter boas condições de padronização do exame. Os pacientes padronizados são preparados especificamente para atuar sempre da mesma maneira em situações de avaliação, envolvendo grande número de examinandos. Preferencialmente, podem ser aproveitados, como pacientes padronizados, pessoas com:

a - problemas de saúde bem conhecidos:

b - habilidade para assimilar instruções e para exibir, com autenticidade e consistência, os atributos desejados (informações sobre sintomas, sinais de exame físico, situações específicas de vida pessoal ou profissional, por exemplo), e

c - tempo livre disponível para submeter-se aos pro gramas de treinamento e para atuar nas sessões de ensino ou de avaliação. Mais freqüentemente, são empregadas pessoas sem qualquer problema de saúde, mas que têm a capacidade de simular, adequadamente, os atributos necessários ("pacientes simulados"). Neste sentido, podem também ser em pregados, como pacientes simulados, atores, profissionais ou amadores, especialmente quando se pretende a simulação de situações que envolvem alto grau de emotividade ou dramaticidade.

Para as finalidades de avaliação de competências clínicas, os pacientes padronizados podem, também, ser instruídos para preencher protocolos de ob- servação, registrando e classificando, em graus de proficiência, o desempenho dos estudantes. Desta maneira, o paciente padronizado pode desempenhar, simultaneamente, os papéis de objeto da avaliação e de examinador.

Vários estudos demonstram que, quando adequadamente treinados, os pacientes padronizados não são distinguidos de pacientes verdadeiros nem pelos examinandos (estudantes) nem por examinadores médicos ou professores ${ }^{22}$.

E também conhecido que, além de desempenhar com eficiência máxima os atributos necessários à realização da anamnese e à comunicação médicopaciente, o paciente padronizado pode ser treinado para simular uma variedade de sinais físicos, como por exemplo, manifestações neurológicas (tremores, corea, hemi paresia, hiperreflexia, etc.), rigidez abdominal, dispnéia, entre outros ${ }^{25}$.

Enquanto instrumento de avaliação de competências clínicas, os pacientes padronizados apresentam algumas qualidades importantes. Entre estas, a possibilidade de permitir a avaliação, sem que haja a presença de uma terceira pessoa (examinador). Desta maneira, ficam minimizadas as influências negativas ligadas à presença de examinadores. Outra importante vantagem do uso de pacientes padronizados é que permitem que todos os examinandos submetam-se à situação de avaliação padronizada, isto é, todos têm contacto com o mesmo caso, nas mesmas condições.

Sendo pacientes verdadeiros, podem, também, dar informações mais fidedignas sobre habilidades de comunicação, em especial sobre aquelas que demandam a abordagem, durante a obtenção da história clínica, de temas sensíveis, que envolvem a privacidade dos pacientes. Adicionalmente, o emprego sistemático de pacientes padronizados exige o delineamento concreto do que é relevante para ser ensinado e avaliado, o que servirá de base para o treinamento do paciente padronizado. Exige, ainda, a definição precisa dos critérios de avaliação do desempenho clínico, a serem, então, delegados previamente ao próprio paciente padronizado.

O emprego desta modalidade de avaliação de manda, entretanto, considerável esforço na sua implementação e envolve custo considerável, pertinente ao treinamento e à remuneração dos pacientes padronizados. Não obstante, este recurso vem sendo crescentemente utilizado, especialmente nas escolas médicas americanas ${ }^{26}$. 


\subsection{A escolha dos métodos de avaliação}

A seleção do método de avaliação deve ser feita, levando-se em conta, prioritariamente, o "que" deve ser avaliado. Este é um requisito fundamental da validade da avaliação. A escolha do método deve, também, ser norteada pela finalidade da avaliação. Nas avaliações somáticas, destinadas a tomar decisões sérias sobre a vida escolar do estudante, é fundamental a aplicação de métodos de maior objetividade, em condições adequadas de padronização, de modo a garantir a fidedignidade da avaliação.

Deve-se, ainda, considerar que uma avaliação abrangente, incidindo sobre uma gama variada de competências e de habilidades, provavelmente, irá re querer a aplicação não de um único método, mas o emprego de vários instrumentos e técnicas, cujos resultados se completarão.

O uso apropriado de qualquer método de avaliação requer que se tenham presentes as suas vantagens e desvantagens e, em especial, as suas limitações. Além disso, na interpretação dos resultados obtidos, devem ser considerados os fatores que, na aplicação de um método específico, exercem influência sobre os resultados verificados. Qualquer que seja a técnica selecionada, independentemente do "que" está sendo avaliado, deve-se ter em conta a questão da amostragem. E absolutamente impossível garantir a cobertura de todo o universo de conteúdos ou toda a gama de habilidades a serem avaliadas. Deste modo, deve-se cuidar para que se disponha de uma amostragem que seja adequada dos pontos de vista quantitativo e qualitativo. O uso de pró-formas ou anteprojetos escritos e a sua discussão subseqüente é um procedimento útil não só para definir uma amostragem satisfatória, como também para a rediscussão do que se pretende avaliar, e para a revisão voltada a decidir, definitivamente, se o método escolhido ou o conjunto de técnicas e instrumentos selecionados é, de fato, efetivamente o mais adequado.

Outro conjunto de fatores que deve ser considerado na escolha dos métodos de avaliação é de ordem operacional e relaciona-se com a colocação em prática da técnica selecionada e com a sua aceitação por parte dos examinandos. Este item deve ser harmonizado com os precedentes, relativos à adequação, validade e fidedignidade do método escolhido.

Por fim, deve-se ter presente, como um conceito básico, subjacente a qualquer processo de avaliação, que a escolha e a subseqüente aplicação de um método para a obtenção de resultados definidos é um meio para a consecução de determinadas metas que resultam em um aprimoramento da educação do estudante, e não um fim em si mesmas.

\section{USOS E FUNÇÕES DE AVALIAÇÃO}

A avaliação do estudante de Medicina, como já se considerou anteriormente, é um processo de colheita de informações que permite subsidiar intervenções positivas na sua educação. Idealmente, a avaliação do estudante deveria ser parte indissociável do processo educacional, sendo aplicada extensivamente, a todo o momento, e sendo reconhecida, especialmente pelo estudante, como um meio eficiente de reforço do aprendizado e de correção de distorções eventualmente presentes. Para o professor, deveria, analogamente, funcionar como um recurso de grande utilidade no controle de qualidade do processo instrucional, bem como constituir oportunidade ímpar de refletir sobre o que está sendo ensinado, em relação ao desejável e ao que foi previamente planejado.

O processo de avaliação permite, também, verificar se o estudante está em condições de progredir nas etapas futuras da sua formação. Adicionalmente, a aplicação dos diferentes instrumentos de avaliação fornece resultados que possibilitam diferenciar os estudantes em graus diversos de conhecimento ou de proficiência em determinadas habilidades. Estes dois últimos aspectos, têm, infelizmente, predominado sobre os primeiros, gerando inconvenientes e distorções, que têm sido reconhecidos em todo o mundo ${ }^{3}$. Acresce-se a isto, a tendência negativa do uso da avaliação predominante- mente para detecção e medida da aquisição de conheci mento factual e não para apreciação de habilidades e de competências mais abrangentes e de ordem mais prática.

$\mathrm{O}$ uso inadequado de diferentes práticas de avaliação tem, por conseguinte, gerado inúmeros inconvenientes, com impacto altamente negativo no processo educacional e nas pessoas nele envolvidas. Um dos inconvenientes mais expressivos é a adoção, pelos estudantes, de um estilo de aprendizado baseado forte mente na expectativa de resultado favorável nos exames que se seguirão. Assim, muitos estudantes, a todo o momento, estudam para "passar" nas provas e não para aprender temas de relevância. Mais ainda, restringem o estudo e o aprendizado àquilo que a tradição ou o pressentimento indicam que fará parte dos exames do final do curso. No caso específico do estu- 
dante de Medicina, este fenômeno adquire relevância particular, na medida em que concorre fortemente para afastar o aluno de atividades práticas em laboratório, enfermarias ou ambulatórios, para se dedicar à memorização de conhecimentos de importância não raro discutível.

Outra distorção notável é o uso, por toda a comunidade de professores e de estudantes, da avaliação somativa como meio de punir os que falham e de premiar os que alcançam as maiores notas Possivelmente, os que falharam e que, freqüentemente, são reprovados, poderiam ter resultado diferente, se houvesse aplicação mais extensiva das modalidades de avaliação formativa, que permitem suprir deficiências e corrigir distorções do aprendizado. Estes estudantes, além das conseqüências sempre graves de reprovação, podem perder a auto-estima e sofrer humilhação frente a seus colegas e professores, com evidente prejuízo ao seu futuro escolar e profissional. Por outro lado, a recompensa das maiores notas a alguns poucos estudantes pode reforçar as distorções do estilo de aprendizado voltado aos resultados de exames, bem como criar expectativas irreais de sucesso na carreira e no desempenho profissional futuro. Mais ainda, a imagem das práticas de avaliação que se associam ao binômio "prêmio-castigo", pode estimular a criação, entre os estudantes, de espírito de competitividade, potencialmente destrutivo para os indivíduos envolvidos, e, certamente, negativo para o ambiente de cooperação mútua que favorece o aprendizado e aumenta o rendimento educacional.

Em seu conjunto, estas distorções contribuem para que as modalidades de avaliação somativa, em geral, e os exames, em particular, tenham adquirido uma conotação francamente aversiva. Conseqüente mente, a perspectiva de submissão a qualquer prova provoca, nos estudantes, um grau inadequadamente alto de ansiedade que, claramente, funciona como fator de influência negativa em seu desempenho.

A busca de meios para a correção do mau uso das práticas de avaliação, bem como para sanar os inconvenientes a ele associados, deve considerar as funções básicas da avaliação e algumas recomendações sobre a estrutura de avaliação a ser adotada pela escola médica ${ }^{3}$. Deve-se ter presente que a avaliação deve servir a:

- monitoramento do currículo e controle da eficiência do ensino e do aprendizado;

- provisão de reforço, aos estudantes e aos professores, como agentes principais do processo do ensino e do aprendizado;

- estímulo e orientação ao aprendizado individual dos estudantes;

- meio de obtenção de consenso sobre o que é importante ensinar e aprender;

- garantia de obtenção de nível adequado de competência e de segurança quanto à obediência a padrões mínimos de qualidade do desempenho profissional dos estudantes que se graduam; o cumprimento desta função pela escola médica é de importância crucial, mormente nos países em que os órgãos de controle do exercício profissional se eximem deste dever

$\mathrm{Na}$ consecução destas metas recomenda-se que:

- todos os procedimentos de avaliação devem ser planejados e utilizados em completa integração com o processo educacional;

- para cada um dos procedimentos escolhidos, devem ser claramente especificados os seus objetivos e a sua relação com as finalidades a que servem.

- para cada um dos métodos selecionados devem ser explicitamente definidos o seu conteúdo e, em especial, o seu efeito potencial sobre o aprendizado dos estudantes;

- todos os métodos de avaliação adotados devem, idealmente, ser providos de altos níveis de validade, fidedignidade e serem viáveis e práticos;

- deve haver um empenho especial na realização freqüente e periódica de procedimentos voltados à avaliação formativa, que devem predominar sobre os de avaliação somativa;

- o planejamento e a execução da avaliação devem privilegiar não só os aspectos cognitivos, mas as habilidades e competências práticas de maior abrangência.

Por fim, deve-se considerar que a avaliação, freqüientemente, traz consequiências para a vida do estudante, o que implica em que haja o maior grau de justiça na aplicação das técnicas e na interpretação dos resultados. Do mesmo modo, a avaliação pode ter importante impacto no planejamento educacional, razão por que é essencial a seleção de métodos de maior objetividade e o seu uso em condições de padronização máxima, para que se possa dispor, ao final do processo, de informações confiáveis. 
TRONCON LE de A. Assessmerit of medical students. Medicina, Ribeirão Preto, 29: 429-439, oct./dec. 1996.

ABSTRACT: Assessment of medical students plays a central role in their education and comprises a key function of medical schools. Assessment may be defined as a process of data gathering aiming at controlling educational procedures and positively influencíng student education. Assessment should cover ali relevantfeatures and invoive methods of undisputable validity, reliability and feasibility. Comprehensive assessment of medical students must include cognitive aspects and clinical skilis composing overali medical competence, as well as attitudes and personal characteristics. Modern methods, such as O.S.C.E. - Objective Structured Clinical Examination, Clinical Performance Examination and the use o Standardized Patients now permits valid, reliable and feasible measurement of clinical competence of medical students. In many medical schools, excessive emphasis in cognitive aspects and in summative examinations aiming at reward some and punish other students have contributed to a negative public image of assessment procedures. More extensive use of formative modalities of evaluation, together with a more judicious choice of valid and reliable techniques may be instrumental in the replacement of assessment in its more genuinous educational function.

UNITERMS: Evaluation. Clinical Competence. Students Medical. Education, Medical.

\section{REFERÊNCIAS BILIOGRÁFICAS}

1 - LOWRY S. Assessment of students. BMJ 306: 51-54, 1993.

2 - WEATHERALL DJ. Examining undergraduate examinations. Lancet 338: 37-39, 1991.

3 - GODFREY RC. Undergraduate examinations - a continuing tyr anny. BMJ 345:765-767, 1995

4 - VIANNA HM. A prática da avaliação educacional: algumas co locações metodológicas. Cad Pesq, São Paulo 69: 40-47, 1989.

5- TYLER RW. Basic principies of curricuium and instruction. The University of Chicago, Chicago, 1949.

6 - POPHAN WJ. Educacional evaiuation. Prentice Hall. Engleword Cliffs, 1975.

7 - GRONLUND NE. Measurement and evaluation in teaching. 5th ed, McMillan Publishing, New York, 1985.

8 - FERREIRA 1. Avaliação de competências básicas. Rev Bras Educ Méd 10:77-81, 1986.

9 - BLOOM BS. Taxonomy of educational objectives. David Mckay, New York, 1983

10- TRONCON LEA et al. Avaliação terminal de competências dos graduandos em Medicina: relato da experiência inicial da Faculdade de Medicina de Ribeirão Preto, Faculdade de Medicina de Ribeirão Preto, Ribeirão Preto, 118 p, 1996.

11 - The ROBERT WOOD JOHNSON FOUNDATION COMMISION ON MEDICAL EDUCATION. Summary Report. JAMA 268: 1144-1145,1992.

12- BLAKE JM; NORMAN GR \& SMITH EKM. Report card from McMaster: Student evaluation at a problem-based medical school. BMJ 345: 899-902, 1995.

13- DAWSON-SAUNDERS B \& PAIVA RA. The validity of a clerk ship performance evaluation. Med Educ 20: 240-245, 1986.

14- STOKES J. The clinicai examination-assessment of clinicai skilis. Medical Education Booklet2. Association forthe Study of Medical Education, Dundee, 1974.

15 - VAN DER VLEUTEN C \& NEWBLE DI. How can we test clinical reasoning? Lancet 345: 1032-1034, 1995.

16 - GLEESON F. The effect of immediate feed-back on clinicai skiils using the OSLER. In: ROTHMAN AI \& COHEN R, eds.
Proceedings, VI Ottawa Conference on Medical Education. Univeristy of Toronto Bookstore, Toronto, p. 412415, 1994.

17- VAN DER VLEUTEN C. Making the best of the "long case". Lancet 347: 704-705, 1996.

18- HARDEN RM et ai. Assessment of clinical competence using objective stwctured ciinicai examination. BMJ 1: 447-451, 1975.

19 - HARDEN RM \& GLEESON FA. Assessment of clinicai com petence using an objective structured clinicai examination (OSCE). Med Educ 13: 39-45, 1979.

20 - TRONCON LEA et ai. Avaliação de habfidades chnicas por exame objetivo estruturado por estações, com emprego de pacientes padronizados: primeira aplicação no Brasil (Parte 1). Rev Bras Educ Med (Em publicação).

21 - VU NV et al.Six years of comprehensive, clinical, perfor mance-based assessment using standardized patients at the Southern Illinois University School of Medicine. Acad Med 67: 42-50, 1992

22- VAN DER VLEUTEN CPM \& SWANSON DB. Assessment of clinical skills with standardized patients: State of the art. Teach Learn Med 2: 58-76, 1990.

23 - RESNICK RK et ai. An O.S.C.E. for the licenciate: report of the pilot project of the Medical Councii of Canada. Acad Med 67: 487-494, 1992.

24- BARROWS HS; COLLIVER JA \& VU NV. The clinical prac tice examination: six-year summary. Southern Illinois University School of Medicine, Springfield, 1988.

25 - BARROWS HS. An overview of the uses of standardized patients for teaching and evaluating clinical skifls. Acad Med, 68: 443-451, 1993.

26 - SWANSON AG \& BROWNELL-ANDERSON M. Educating medical students. Acad Med 65 (Suppl): S1-S46, 1993.

27- VIANNA HM. Avaliação educacional nos "Cadernos de Pesquisa. Cad Pesq, São Paulo 80: 100-1 05, 1992.

28 - MCMANNUS 1. Examining the educated and the trained. Lancet 345: 1151-1153, 1995.

Recebido para publicação em 23/10/96 Aprovado para publicação em 11/12/96 